\title{
Erratum to: Numerical modelling of phase-change material used for PV panels cooling
}

\author{
Assia Sellami ${ }^{1, a}$, Rabie Elotmani ${ }^{1}$, Khalid Kandoussi ${ }^{1}$, Mohamed Eljouad ${ }^{1}$, Abdelowahed Hajjaji ${ }^{1}$, and \\ M'Hamed Boutaous ${ }^{2}$ \\ ${ }^{1}$ Chouaib Doukkali University of El Jadida, National School of Applied Sciences, Science Engineer Laboratory for Energy \\ (LabSIPE), EL Jadida, Morocco \\ 2 CETHIL, UMR 5008, CNRS, INSA Lyon, Université Lyon 1, F-69621 Villeurbanne CEDEX, France
}

Original article: Eur. Phys. J. Plus (2017) 133: 553, https://doi.org/10.1140/epjp/i2017-11817-9

Received: 12 June 2018

Published online: 10 July 2018

(C) Società Italiana di Fisica / Springer-Verlag GmbH Germany, part of Springer Nature, 2018

We would like to inform the reader that there is a reference, which we omitted to mention in our bibliographical references, because we became aware of its existence only after the publication of our work. It is the conference paper by Groulx and Biwole [1].

The authors studied the relation between the natural convection and the inclination of the PV/PCM system. They found that in an inclination of $90^{\circ}$, the natural convection disappears completely and the melting process is dominated by conduction only, while the temperature is maintained at a low value for $134 \mathrm{~min}$. However, for an inclination from $0^{\circ}$ to $60^{\circ}$, the melting process is faster than in the vertical case, because of the natural convection role enabling energy to get transferred more quickly to the back side of the system. The authors' work is based on the latest study of Huang et al. [2], in which the same problem was treated (same model, same size and boundary conditions).

Let us thus, in our turn, maintain the same model by which we studied, in the presented work, an inclined system by a predefined angle of $30^{\circ}$, corresponding to the maximum incident irradiation given by the orientation of the PV panels in our region (city of EL Jadida, Morocco). We worked under the same conditions as Biwole et al. [3], Huang et al. [2] and Groulx and Biwole [1], in order to analyze the velocity field inside the PCM while considering natural convection.

We confronted the evolution of the front melting with the work of Groulx and Biwole [1], and we found that our system melts faster; only 80 minutes are needed, as is shown in table 1.

Table 1. PCM melting time with different inclination.

\begin{tabular}{|c|c|c|}
\hline \multirow{2}{*}{ Angles } & \multicolumn{2}{|c|}{ Melting time } \\
\cline { 2 - 3 } & Present work & Groulx and Biwole \\
\hline $30^{\circ}$ & $80 \mathrm{~min}$ & $104 \mathrm{~min}$ \\
\hline $60^{\circ}$ & $97 \mathrm{~min}$ & $108 \mathrm{~min}$ \\
\hline $90^{\circ}$ & $102 \mathrm{~min}$ & $134 \mathrm{~min}$ \\
\hline
\end{tabular}

The difference in the melting time between inclinations is explained by the dominance of natural convection, in which the melting time decreases with the decrease in the PV inclination. Table 1 shows a comparison between the results of Groulx and Biwole [1] for the evolution of melting time of RT25 with three different inclinations $\left(30^{\circ}, 60^{\circ}\right.$, $90^{\circ}$ ) and those of our work.

\footnotetext{
a e-mail: sellami.assia@gmail.com
} 
Accordingly, to explain the natural circulation of the melt front of the PCM, the phenomenon of internal convection is relevant and depends on the specification of the geometry and orientation of the enclosure which, in our case, is heated from the side of the PV panel. On the other hand, the inclination $\theta$ has a dramatic effect on the heat transfer and flow characteristic inside the PCM domain. As $\theta$ decreases below $90^{\circ}$, the heat convection increases and improves mainly by increasing the velocity of the melted front over the surface.

In addition, the buoyancy force in the vertical case, acts exclusively to induce motion in the streamwise direction. However, in the inclined case, there are two components of the buoyancy force, which are normal and parallel to the streamwise direction. These conditions may strongly influence the development of the motion in the two directions.

Basically, we have noticed the same physical phenomenon with Groulx and Biwole [1]. However we highlighted a difference in the melting time of PCM. Moreover, in order to verify the accuracy of the melting front evolution during phase change, we validated our numerical work with the model of Viskanta, who used the Neumann solution, based on the Stefan problem in natural convection, to calculate the melted volume fraction and analyze the evolution of the solid-liquid front inside the PCM. This constitutes a real added value for our article.

\section{References}

1. D. Groulx, P.H. Biwole, Solar PV passive temperature control using phase change materials, in Proceedings of the 15th International Heat Transfer Conference, IHTC-15 (2014) https://doi.org/10.1615/IHTC15.tmg.008886.

2. M. Huang, P. Eames, B. Norton, Int. J. Heat Mass Transfer 47, 2715 (2004).

3. P.H. Biwole, P. Eclache, F. Kuznik, Energy Buildings 62, 59 (2013). 